\title{
Revitalisasi Masjid melalui Kepedulian Sosial Lembaga Takmir Masjid Nahdlatul 'Ulama (LTM NU) terhadap Komunitas Pengemudi
}

\author{
Pipin Yosepin ${ }^{*}$ dan Baharuddin Husin \\ Fakultas Agama Islam, Universitas Islam As-Syafi'iyah, Jakarta \\ ${ }^{*}$ Email: pipin.nurjannah@gmail.com
}

\begin{abstract}
Islamic civilization was built by making the mosque as the center of muslim's activities. Nowdays, however, the function and role of the mosque are dwarfed only as a place of ritual worship. The Mosque management Organization of Nabdlatul 'Ulama Mosque (LTM NU) revitalize the function of the mosque through social awareness activities for the community. This study describes LTM NU's social awareness activities towards driver community in Central Jakarta as part of the mosque revitalization effort. This study uses qualitative methods and descriptive analysis by collecting data through participant observation, interviews with stakeholders of LTM NU and the driver community in Central Jakarta, and data analysis using triangulation. The results of the study show that: 1) LTM NU bas a sustainable program of revitalization for maximizing mosque functions. 2) LTM NU succeeded in conducting da'wah activities to the driver community through persuasive da'wah communication that created da'wah civilization. This research contributes to the development of da'wah science, especially the study of Islamic community development.
\end{abstract}

Keywords: Da'wah; Social Awareness; Persuasive; LTM NU

\begin{abstract}
ABSTRAK
Peradaban Islam dibangun dengan menjadikan masjid sebagai sentrum kegiatan umat Islam. Namun saat ini fungsi dan peran masjid dikerdilkan hanya menjadi tempat ibadah ritual semata. Lembaga Takmir Masjid Nahdlatul 'Ulama (LTM NU) berupaya melakukan revitalisasi fungsi masjid melalui kegiatan kepedulian sosial kepada masyarakat. Penelitian ini menjelaskan kegiatan kepedulian sosial LTM NU terhadap komunitas pengemudi di Jakarta Pusat sebagai bagian dari upaya revitalisasi masjid. Penelitian ini menggunakan metode kualitatif dan analisis deskritif dengan pengumpulan data melalui participant observation, wawancara dengan informan stakeholder LTM NU serta komunitas pengemudi di Jakarta Pusat, dan analisis data dilakukan dengan triangulasi. Hasil penelitian menunjukkan bahwa: 1) LTM NU memiliki program revitalisasi dalam memaksimalisasi fungsi masjid yang berkelanjutan. 2) LTM NU berhasil melakukan aktivitas dakwah kepada komunitas pengemudi melalui komunikasi dakwah persuasif yang menciptakan civilization dakwah. Penelitian ini memberikan kontribusi bagi pengembangan ilmu dakwah, khususnya kajian pengembangan masyarakat Islam.
\end{abstract}

Kata Kunci : Dakwah; Kepedulian Sosial; Persuasif; LTM NU 


\section{PENDAHULUAN}

Keberadaan masjid sangat penting bagi umat Islam. Di Indonesia, dengan penduduk mayoritas umat Islam, jumlah masjid dan musala mencapai 1.070.000 (Kementrian Agama RI, 2009). Bahkan menurut data Lazuardi Biru tahun 2010, kurang lebih 80 persen masjid menggunakan amaliyah ala NU dalam hal beribadah, misalnya qunut saat salat subuh, wirid setelah imam salam, azan Jumat dua kali dan sebagainya (LTM PBNU, 2015: 15).

Masjid merupakan sarana dalam beribadah bagi umat Islam kepada Allah Swt. Secara tektual masjid berasal dari kata "sajada" (مَنْجِدُ yang berarti meletakkan wajah ke bumi/tanah (Mandzur, 1940). Secara istilah masjid memiliki arti setiap tempat di bumi yang dapat dilakukan untuk bersujud. Allah menjadikan bumi sebagai tempat salat dan sarana bersuci (tayammum) dan jika umat-Nya datang pada waktu salat (di suatu tempat), maka diharuskan salat (di sana). Hal tersebut tertuang dalam sabda nabi : "Dan bumi ini dijadikan bagiku sebagai tempat salat dan sarana bersuci (tayammum). Maka siapapun dari umat-Ku yang datang waktu salat (di suatu tempat), maka hendaklah ia salat (di sana) (H.R. al-Bukhari dan Muslim). Keberadaan Masjid merupakan bentuk pengabdian kepada Allah. Sikap egaliter dapat dilihat dari kebersamaan, dan ghirah jamaah.

Dewasa ini masjid atau musala dalam kehidupan sehari-hari dimaknai sebagai bangunan tempat salat. Pada kenyataannya, saat ini banyak masjid dibangun dengan megahnya, namun masih kurang berfungsi secara optimal dan masih perlu usaha untuk memakmurkannya. Manusia sebagai khalifah Allah di bumi memiliki tugas untuk memakmurkan masjid dan memakmurkan jamaahnya, karena masjid sebagai rumah Allah di bumi. Keberadaan fungsi rumah Allah begitu penting di mata umat Islam sehingga jumlah masjid begitu banyak namun pengelolaannya masih sangat memprihatinkan. Menurut Ali Sobirin, masjid sebagai benteng PBNU (Pancasila, Bhinneka Tunggal Ika, NKRI, dan UUD 1945) harus diberdayakan. "Sekarang ini di masyarakat sedang terjadi anomali budaya. Di satu sisi semangat keberagamaan meningkat, namun pada saat yang sama nilainilai prinsipil keagamaan terkesampingkan. Satu sisi semangat membangun masjid megah begitu luar biasa, pada saat yang sama masjidnya sepi-sepi saja" (Sobirin: 2018).

Peran dan fungsi masjid sesungguhnya sangat strategis. Hal ini ditunjukkan Rasullulah Saw ketika berhijrah ke Madinah. Langkah pertama yang dia tempuh yaitu dengan membangun masjid Nabawi berlantaikan tanah dengan atap pelepah kurma. Mulai dari situ Nabi Muhammad mengajarkan kepada para sahabat tentang akidah Islam. Rasullulah pun menjadikan masjid Nabawi sebagai sentrum kegiatan, mulai dari dakwah, pendidikan, pemberdayaan masyarakat, pengembangan ekonomi, serta pelayanan sosial. Sehingga di masa Rasullulah Saw, masjid menjadi sentral kegiatan dakwah dan pusat kebudayaan Islam dan kota Madinah menjadi pusat peradaban. Dengan demikian masjid memiliki pengaruh 
besar dalam kehidupan masyarakat.

Fungsi dan peran masjid yang begitu besar pada masa lalu, saat ini berubah menjadi kurang diperhatikan Ali Sobirin (2018) berpendapat bahwa yang lebih memprihatinkan, masjid-masjid sekarang sepi dengan aktivitas pemuda. Padahal, merekalah yang akan menerima mandat umat Islam berikutnya. Hal tersebut terjadi karena faktor eksternal dan internal masjid. Secara eksternal, daya tarik aktivitas di luar masjid sangat kuat. Para pemuda ditawari beragam kreasi kebebasan dan kesenangan dengan aneka bentuk dan intensinya. Sedangkan, pada saat yang sama, secara internal, masjid terkesan kaku dan jumud, serta jauh dari kepentingan pemuda. Masjid belum mengakomodir kepentingan pemuda.

Permasalahan kompleks kurang optimalnya fungsi masjid terjadi karena saat ini masjid identik sebagai tempat solat saja. Kondisi ini disebabkan karena pengelola masjid yang tidak kompeten (LTM PBNU, 2015: 15). Sebagian pengelola masjid sibuk dengan pekerjaan utamanya masing-masing dan tidak fokus mengurus dan mengelola masjid. Bahkan banyak pengelola masjid tidak mempunyai kemampuan manajerial dan keuangan. Akibatnya masjid dibiarkan begitu saja dan hanya dijadikan sebagai tempat salat. Padahal banyak potensi masjid yang dapat digali dan dikembangkan lebih lanjut. Namun, karena tidak dikelola secara optimal akhirnya masjid menjadi terlantar.

Pengelolaan masjid yang kurang baik ini mengundang orang di luar jamaah masjid ikut memperhatikan. Mereka membantu, mengelola masjid dan memakmurkan masjid dengan berbagai aktivitas. Namun, di beberapa masjid diketahui para pengelola baru masjid tersebut memiliki agenda lain yaitu memasukkan faham dan ideologi yang berbeda kepada jamaah. Perlahan tapi pasti pengelola masjid ini mengubah amaliyah ubudiyah yang selama ini sudah dipraktikkan di masjid tersebut dengan amaliyah ubudiyah baru. Perbedaan pendapat antara pengurus masjid yang lama dengan yang baru menjadi konflik baru dalam pengelolaan masjid. Masjid menjadi tempat rebutan kelompok keislaman di Indonesia. Padahal sejatinya masjid sebagai pusat dakwah dalam memberdayakan masyarakat.

Dakwah sebagai proses kegiatan dalam mengajak manusia kepada Al-Islam selain dilakukan dengan lisan, tulisan, juga dilakukan melalui aksi sosial (Fakruroji, 2017: 3). Dakwah juga bisa dilakukan dengan mengelola kegiatan melalui lembaga Islam yang dilakukan dalam program yang tersistematisasi, terkoordinasi, tersinkronisasi, dan terintegrasi dengan sumber yang tersedia sehingga mencapai sasaran perubahan yang dituju. Dalam praktiknya dakwah mengandung dan melibatkan penyampaian pesan, informasi yang disampaikan dan penerima pesan. Setiap manusia membutuhan dakwah, arena dakwah senantiasa diperlukan untuk mengingatkan manusia selalu melakukan amar ma'ruf nabi munkar, dan bahwa hidup penuh dengan pilihan dan jalan yang baik dan buruk.

Kebutuhan terhadap dakwah dan ukhuwah Islamiyah yang menjamin keutuhan dan kesatuan umat dirasakan semakin penting diwujudkan dalam 
komunitas masyarakat. Pentingnya persaudaraan Islam (al ukbuwah Islamiyah) merupakan ajaran dasar Islam dalam bidang sosial. Ia merupakan pilar dan tonggak yang berfungsi sebagai penyanggah kesatuan dan kekuatan umat Islam. Dalam Islam, ukhuwah seseorang diikat dengan kesatuan aqidah. Sebagaimana firman Allah dalam surat Al Hujurat [49]: 10. "Sesungguhnya orang-orang yang beriman itu bersaudara. Sebab itu damaikanlah (perbaikilah hubungan) antara kedua saudaramu itu dan takutlah terhadap Allah, supaya kamu mendapat rahmat" (Depag RI, 2008: 836).

Dalam menjaga hubungan sosial di masyarakat, kerja sama dalam komunitas bisa diwujudkan dengan memiliki sikap peduli. Kepedulian sosial merupakan sikap empati pada sesama anggota masyarakat/komunitas dalam mewujudkan minat atau kehendak kita dalam membantu orang lain. Dalam Islam sikap peduli kepada sesama sangat dianjurkan.

Kepedulian sosial dalam kehidupan bermasyarakat lebih sering diartikan sebagai perilaku yang baik dari seseorang terhadap orang lain di sekitarnya. Kepedulian sosial biasanya dimulai dari kemauan memberi bukan menerima (Iimaziah: 2012). Kepedulian sosial juga berarti sikap untuk mengasihi yang kecil dan menghormati yang besar dimana orang-orang dalam kelompok 'besar' mengasihi dan menyayangi orang-orang dalam kelompok 'kecil' begitu pula sebaliknya. Kepedulian sosial mengajarkan betapa perlunya memupuk sikap yang baik dalam hidup seseorang. Sikap dan tindakan yang selalu ingin memberi bantuan pada orang lain dan masyarakat yang membutuhkan adalah bentuk kepedulian sosial. Kepedulian sosial juga merupakan keterlibatan pihak yang satu kepada pihak yang lain dalam merasakan apa yang sedang dialami atau dirasakan oleh orang lain (Zuchdi, 2011: 170). Kepedulian sosial merupakan bagian dari aplikasi dakwah dalam kehidupan masyarakat termasuk warga di Jakarta.

Di era modern saat ini interaksi sosial warga di kota metropolitan seperti Jakarta, mulai berkurang karena budaya masyarakat perkotaan yang memiliki rutinitas dan aktivitas yang tinggi. Kehidupan warga ibu kota yang penuh kesibukan diisi dengan kehidupan sosial yang kian pragmatis. Dalam keseharian warga beraktivitas untuk memenuhi kebutuhan hidup menurut kemampuannya. Mereka harus berjuang mencari nafkah setiap hari bagi diri dan keluarganya agar tetap bisa bertahan hidup sehingga tingkat kepedulian sosial mereka menjadi rendah.

Realitas kehidupan di kota Jakarta seperti itu sesuai dengan kondisi warganya yang termasuk kategori kaum urban yang berasal dari berbagai daerah. Mereka datang ke ibu kota karena faktor ekonomi yang kuat untuk mendapatkan penghidupan lebih baik. Di daerah perputaran ekonomi kebanyakan hanya terjadi di siang hari dan malam hari tidak ada kegiatan ekonomi. Sebaliknya, di Jakarta kegiatan ekonomi bisa dilakukan siang dan malam, bahkan sampai pagi pun aktivitas masyarakat ibu kota tidak pernah terhenti. Kerasnya persaingan untuk hidup yang begitu kuat tidak jarang menjadikan warga saling menjatuhkan, dan 
menutupi sikap peduli kepada sesama. Meskipun kondisinya begitu, para pendatang dari berbagai daerah tetap datang ke ibu kota. Harapan memperoleh rezeki yang lebih baik mendorong masyarakat daerah, seperti dari Tegal datang dan tinggal di Jakarta menjadi pengemudi bajaj, sopir mikrolet atau taksi.

Komunitas sopir bajaj, mikrolet, taksi, dan ojek adalah komunitas masyarakat menengah ke bawah perkotaan yang mayoritas beragama Islam. Mereka banyak menghabiskan waktu di jalan dan gang-gang sempit sehingga memiliki ruang interaksi yang terbatas hanya dalam komunitas sesamanya. Meskipun begitu, mereka mencoba menjaga kepedulian terhadap sesamanya. Kerasnya ibu kota membuat mereka tegar dan kuat, tetap menjaga persaudaraan di antara sesamanya sebagai sebuah komunitas yang dibangun atas dasar rasa kepedulian.

Sesuai dengan kodratnya, manusia secara hakiki merupakan makhluk sosial dimana sejak dilahirkan ke dunia mereka menjadi makhluk yang saling membutuhkan satu sama lainnya (Gerungan, 1996: 4). Ketika tumbuh manusia membutuhkan orang lain untuk memenuhi kebutuhan-kebutuhannya. Sebagai makhluk sosial (bomo socialis), manusia membutuhkan manusia lain. Tidak cukup hanya mengandalkan kekuatannya sendiri. Mengisi kehidupan dengan kegiatan saling membantu dan memikirkan kepentingan orang lain merupakan tindakan terpuji, yang sering disebut sebagai peduli atau kepedulian, yaitu merasakan kekhawatiran tentang orang lain atau sesuatu (Yaumi, 2014: 77). Kepedulian merupakan sikap saling menghormati, mengasihi, serta peduli Kepada sesama manusia dalam berbagai macam kondisi dan keadaannya.

Sikap kepedulian sosial dapat ditunjukkan dengan memperlakukan sesama teman atau orang-orang di sekeliling dengan bertindak positif, seperti mau berbagi, membantu dan bekerja sama. Hal ini sebagaimana diungkapkan Mary Bahr (dalam Mcelmeel, 2002) Caring is the act of being concerned about or 4 interested in another person or situation. It is feeling or acting with compassion, concern, or empathy. People who care about others (buman or animal) show their feelings through their actions. That caring does not stop when there is a death — and there are ways to demonstrate one's caring attitude. Identify the characters who about one another, and then explain how they demonstrated their caring attitude.

Rendahnya kualitas kepedulian sosial masyarakat di ibu kota ini mendorong Lembaga Ta'mir Masjid NU ikut berkontribusi menyelesaikannya. LTM NU memandang perlu meningkatkan kepedulian sosial melalui upaya revitalisasi fungsi masjid agar bisa memenuhi kebutuhan jamaah baik dalam kegiatan ibadah ritual maupun dalam pembinaan aspek wawasan sosial, ekonomi dan lainnya (LTM NU, 2017: 15). Revitalisasi secara lesikal bermakna proses, cara, perbuatan menghidupkan atau menggiatkan kembali (KBBI, 2017). Revitalisasi fungsi dan peran masjid di abad ke -15 Hijirah memerlukan tuntunan yang profesioanl agar organisasi takmir masjid lebih efektif dalam menghadapi era global (Hasil Rapat Pimpinan Nasional LTM PBNU, Region V di Palangkaraya, 2015).

Lembaga Takmir Masjid (LTM) yang berada di bawah naungan Nahdlatul 
'Ulama (NU) melakukan revitalisasi masjid dengan terlibat dalam dakwah kepada komunitas pengemudi di Jakarta Pusat. Sikap empati pada kaum marginal dalam kegiatan dakwah LTM NU ditunjukkan dalam berbagai aksi peduli sosial. Penelitian ini menggambarkan tentang revitalisasi masjid melalui kegiatan kepedulian sosial LTM NU terhadap komunitas pengemudi di Jakarta Pusat. Pertanyaan penelitian di antaranya: bagaimana program revitalisasi masjid yang dilakukan oleh LTM NU?, dan bagaimana aktivitas dakwah LTM NU pada komunitas pengemudi di Jakarta Selatan melalui program kepedulian sosial? Penelitian ini menggunakan metode kualitatif dan analisis deskriptif. Pengumpulan data dilakukan melalui participant observation, wawancara dengan informan stakeholder LTM NU serta komunitas pengemudi di Jakarta Pusat. Sedangkan analisis data dilakukan dengan triangulasi.

\section{HASIL DAN PEMBAHASAN}

\section{Program Revitalisasi Masjid LTM NU}

LTM NU merupakan salah satu lembaga takmir masjid di Pengurus Besar Nahdlatul 'Ulama (PBNU) yang memiliki andil dalam mengoptimalisasikan fungsi masjid. Setelah beberapa kali Rapimnas LTM NU di seluruh Indonesia memiliki jaringan struktural 33 PWNU, 4400 PCNU, 2.630 MWC, 37.125 PR dengan program kerjanya melakukan strategi dakwah merevitalisasi LTM NU.

Revitalisasi Lembaga Takmir masjid PBNU merupakan proses mengoptimalkan kembali fungsi Masjid dengan tujuan untuk mempertegas identitas NU di masjid dengan membangkitkan kembali semangat militansi ke NU-an di setiap level PWNU, PCNU, MWC serta pengurus ranting NU di seluruh Indonesia. Selain itu LTM NU membangun kepemimpinan dan perkhidmatan di wilayahnya masing-masing sebagai pemimpin dan pelayan umat. Sebagai pemimpin umat pengurus LTM NU harus bemental mubarrik (penggerak) yang mampu menggerakkan jamaahnya dan membangun generasi penerus NU di masjid-masjid dan musola-musola. Mubarrik inilah yang harus mampu menjalankan 7 agenda revitalisasi masjid yang sudah didesain oleh LTM NU (lihat tabel 1).

Gerakan revitalisasi masjid menurut KH. Abdul Manan (LTM NU: 2017) dituangkan dalam tujuh aksi memakmurkan masjid dengan memberikan doktrin gerakan yaitu Alharokatul Barokah. Sejak dilantik menjadi ketua LTM PBNU 2010 KH. Abdul Manan memulai revitalisasi LTM NU dengan beberapa langkah yaitu: pertama membangun dan meletakkan fondasi kelembagaan yang kuat dan merampingkan pengurus yang terdiri dari aktivis, praktisi dan tokoh, serta menyamakan persepsi serta sosialisasi rencana LTM NU 5 tahun ke depan. Langkah selanjutnya KH. Abdul Manan membangun dan memperkuat networking melalui kegiatan konsolidasi baik struktural maupun kultural, bahkan dengan 
pihak-pihak terkait baik swasta maupun pemerintah yang mau bersinergi dengan program kegiatan LTM PBNU dengan pola saling memberi manfaat.

Tabel 1. Program Kegiatan Memakmurkan Masjid LTM NU

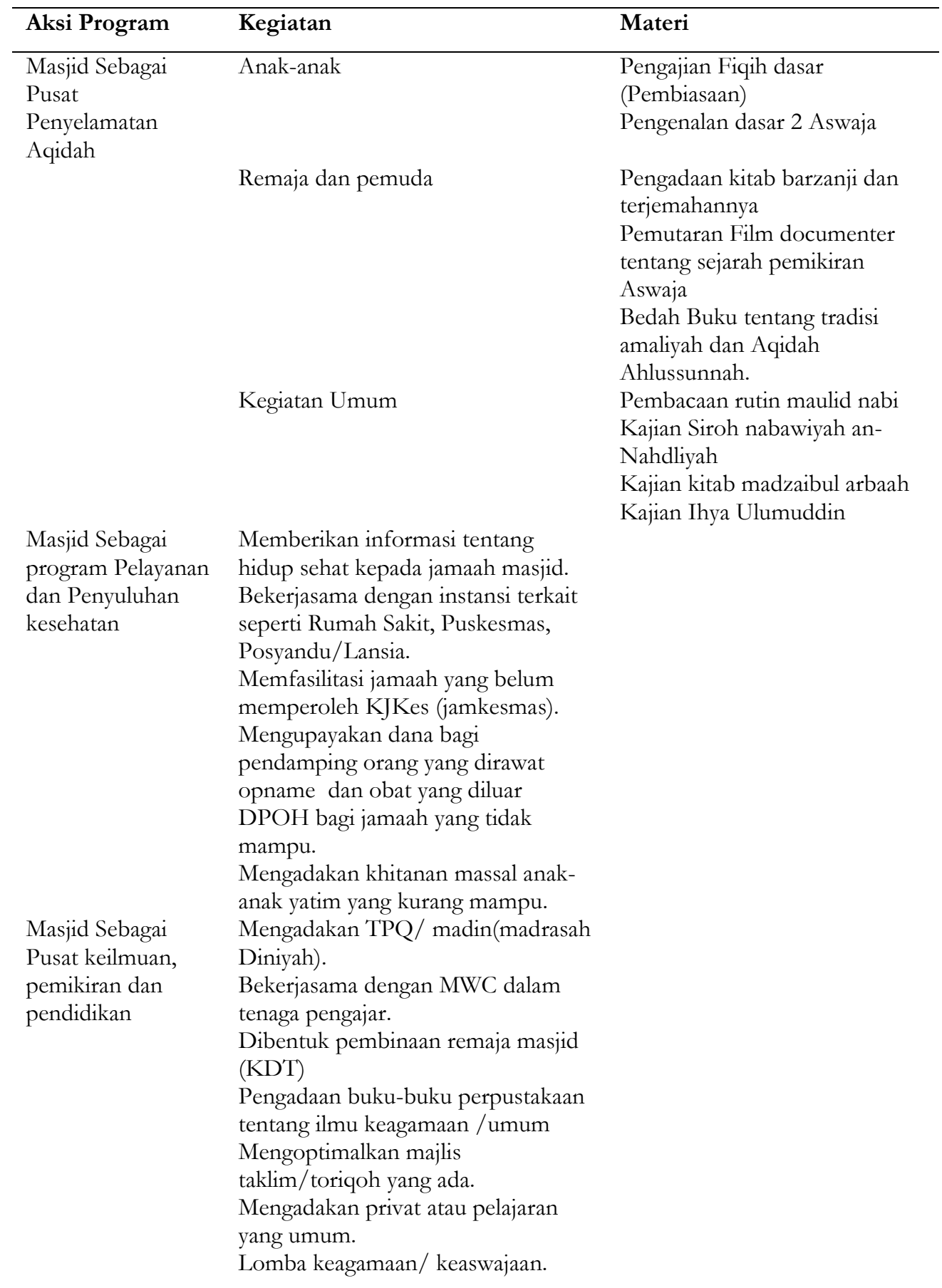


Kursus Bahasa Arab

Masjid Sebagai Sumber Pendanaan
pusat
Pengembangan
Ekonomi

Aksi Pengembangan Ekonomi

\author{
Iuran/infaq jamaah \\ Gismas (Gerakan infaq \\ Sadaqah memakmurkan Mesjid \\ Donatur Tetap \\ Mendirikan Koperasi Serba \\ Usaha \\ Melayani usaha jasa: \\ Pembayaran PDAM, Listrik, \\ usaha sewa perabotan hajatan, \\ dan penjualan kalender dan air \\ mujahadah, mendirikan toko, \\ mengembangkan ekonomi \\ produktif. (usaha).
}

\section{Masjid sebagai Pusat dakkwah Islam Rahmatan Lil 'alamin}

Masjid sebagai pusat kepedulian sosial
Mengadakan kajian kitab Kuning Mengadakan PHBI

Mengadakan pelatihan-pelatihan tilawatil quran, khitobah, khotib, bilal dan muadzin, tajhizul janazah Mengadakan festival anak sholih Mengadakan latihan manasik haji Mewujudkan Radio/TV/ komunitas Mewujudkan Mading Mengadakan Gebyar senin Islami Melaksanakan gema takbir Mengadakan Bahtsul Masail Menjenguk orang/jamaah yang sakit Membantu orang/jamaah yang kena musibah (kematian dll.)

Renovasi rumah warga yang tidak layak huni

Mengadakan kegiatan nikah dan khitanan masal.

Membantu/membimbing dari sakaratul maut sampai proses pemakaman.

Mengadakan pelatihan perawatan jenazah

Mengadakan bakti sosial kepada: kesehatan, pengobatan gratis dan cek kesehatan gratis, santunan yatim dan fakir miskin, donor darah, korban bencana alam.

Beasiswa untuk anak yang berprestasi dar warga kurang mampu.

Menerima dan menyalurkan daging kurban. 
Mudik Gratis setiap tahun bagi masyarakat yang tidak mampu. BBM BERKAH (bersih-bersih masjid) di seluruh Indonesia

Mendoakan orang meninggal istighotsah.
Mengadakan jamiyyah tahlil dan

Pengajian Kitab Kuning

Adanya Mujahadah dan majelis

thoriqoh

Sering mengadakan pengajian

masal/arwahan masal

Melaksanakan salat gaib setiap $b a^{\prime} d a$

salat berjamaah

Memfasilitasi permohonan salat gaib

pada masjid sekitar

Pelatihan mengurus prosesi

kematian

Rutinan khitmil quran

Menggiatkan salat jamaah maktubah

Pelatihan tahlil bagi masyarakat.
Kegiatan harian: 1,10

Kegiatan Mingguan : 1, 3, 5, 6

Kegiatan Bulanan: 9

Kegiatan Tahunan: 4

Kegiatan Kondisional : 7,8

Sumber : LTM PBNU, Pedoman Muharrik dan Ta'mir Masjid NU

Tabel 1 menggambarkan bahwa Sejak 2010-2015 LTM NU memilih strategi dalam membangun kepercayaan dengan menjadi lembaga yang eksis dan dipercaya. LTM NU memulai gerakannya dengan mengadakan halaqah-halaqah, seminar, pelatihan khotib, Imam, pelatihan pemulasaraan jenazah HIV/AID, menyelenggarakan posko lebaran. Posko berbasis masjid ini tersebar mulai dari Merak Banten sampai Ketapang- Banyuwangi, Jawa Timur. Selain itu LTM NU melaksanakan kegiatan event 605 muallaf menulis mushaf Al-Qur'an $30 \mathrm{Juz}$ di Taman Mini Indonesia Indah yang diikuti ratusan muallaf termasuk keturuan Tionghoa di Jakarta dan sekitarnya. Selain itu LTM NU mengundang astronomi Boscha dan ahli Falaqiyah dari internal NU untuk mengedukasi para takmir masjid melalui seminar Rusdul Qiblat. Program besar yang terus berlanjut dan dijalankan sampai saat ini yaitu program gerakan infaq-sodaqoh memakmurkan Masjid \& Masyarakat (GISMAS) yang digeraakan oleh mubarrik-mubarrik di seluruh cabang dan ranting di nusantara. Program lain yang juga mendapat perhatian khusus dari LTM NU adalah pemberdayaan ekonomi masyarakat khususnya para pemuda masjid yang dikemas dengan program MasNU Payment dan Mubarrik Preneur. Program MasNu Payment ini adalah aplikasi pembayaran yang berbasis masjid, bentuknya multi payment seperti membayar cicilan listrik, PDAM, pulsa dan lain sebagainya. Tahun 2013 lalu MasNu Payment dibuat untuk masyarakat dan aplikasinya diperuntukkan bagi masjid-masjid. Sedangkan Mubarrik Preneur adalah program yang mengarahkan bahwa mubarrik masjid mempunyai usaha yang mandiri contohnya seperti dalam MasNu Payment. Mubarrik yang mengurus masjid dapat penghasilan tambahan dari MasNu Payment, misalkan membeli pulsa, bayar listrik ada selisih, dan mubarrik dapat 
selisih keuntungan usaha tersebut. Selain itu juga ada workshop pelatihan salat sempurna cara Rasulullah, haji dan umroh, tabungan kurban dan sebagainya.

Sampai saat ini program kepedulian sosial tersebut masih belum sepenuhnya berjalan. Kegiatan lainnya LTM NU memberikan pelayananan kepada umat dbuafa dengan menyandingkan kegiatan posko lebaran dengan kegiatan Mudik Gratis. LTM NU melayani umat yang mau berlebaran dan pulang kampung ke daerahnya masing-masing dan program kegiatan ini sudah berjalan lancar dalam dua tahun terakhir. Berikut gambaran program kegiatan memakmurkan masjid yang dilakukan LTM NU.

Dengan mengaktualisasikan fungsi dan peran masjid maka masjid ditempatkan pada posisinya dalam masyarakat Islam. Masjid menjadi sentral kegiatan umat dalam mensosialisasikan kebudayaan dan nilai-nilai Islam serta menjadi gerakan dalam dakwah Islamiyah. Dakwah menjadi sebuah proses atau kegitan menyeru, mengajak dan mengingatkan agar umat bisa mengamalkan ajaran Islam dalam kesehariannya (Hasanah, 2011: 3). Menurut Kustadi Suhandang (2014: 4) pada prinsipnya dakwah Islamiyah merupakan komunikasi yang Islami. Seperti halnya kegiatan mudik gratis yang diadakan LTM NU untuk masyarakat dhuafa di kota Jakarta. Program mudik gratis ini direspon oleh masyrakat dhuafa di Jakarta dan sekitarnya, terdiri dari para pengemudi bajaj, mikrolet, taksi, tukang ojek, pedangan asongan, pemulung dan lain-lain yang sebagian besar berasal dari daerah Tegal. Mereka tergabung dalam komunitas Paguyuban Berkah Perantau Nusantara". Fasilitas ini membuat mereka gembira karena fasilitas yang diberikan memudahkan mereka pulang ke kampung halamannya. Dalam dakwah metode ini disebut dengan dakwah qauliah yaitu dakwah dengan informasi yang membawa kabar gembira (Suhandang: 2014: 94). Program mudik gratis ini adalah salah satu kegiatan LTM NU sebagai sarana dalam mewujudkan fungsi masjid sebagai pusat gerakan kepedulian sosial. Respon masyarakat menanggapi informasi ini sangat positif dan beberapa penumpang yang ikut mudik tersebut akhirnya sadar bahwa lembaga LTM NU bisa menampung aspirasi masyarakat. Dalam dua tahun terakhir LTM NU setiap menjelang lebaran atau hari raya Idul Fitri, LTM NU memiliki program menyelenggarakan mudik gratis untuk masyarakat (Mujahidin, Wawancara, tanggal 8 Oktober 2017).

\section{Aktivitas Dakwah LTM NU pada Komunitas Pengemudi}

Kebutuhan dakwah khususnya pada komunitas pengemudi di Jakarta pun menjadi sebuah fenomena yang menjadi sasaran dakwah Lembaga Takmir masjid PBNU dalam menyikapi kebutuhan dakwah umat. Sekelompok pengemudi di Jakarta Pusat yang terdiri dari sopir bajai, sopir mikrolet, sopir taksi dan tukang ojek pedangan asongan, rata-rata berasal dari daerah Tegal. Mereka menjadi sebuah komunitas khusus di daerah Jakarta. Kehidupan kelompok ini terbentuk karena profesi yang sama dan budaya yang mereka memiliki kesamaan. Melalui 
kesamaan tersebut muncul interaksi dan komunikasi yang efektif dalam berbagai kegiatan. Komunitas tersebut ternyata mempunyai kekuatan dalam persatuan dan persaudaraan sehingga dapat mewujudkan kepedulian sosial di dalamnya. Hal ini sesuai dengan makna sikap kepedulian sosial sebagai perasaan bertanggung jawab atas kesulitan yang dihadapi oleh orang lain di mana seseorang terdorong untuk melakukan sesuatu untuk mengatasinya. Kepedulian sosial di dalam kehidupan bermasyarakat lebih diartikan sebagai perilaku baik dari seseorang/lembaga terhadap orang lain (komunitas) di sekitarnya yang butuh pertolongan karena ditimpa musibah atau kesulitan. Dalam Islam sikap peduli sangat dianjurkan. Hal ini menjadi aplikasi bentuk luhur budi pekerti seseorang kepada sesamanya.

Karakter mad'u, seperti komunitas pengemudi-pengemudi ini menunjukkan bahwa adanya komunikasi dakwah LTM NU dalam menjawab kebutuhan spiritual mereka. Dimana kesadaran agama muncul ketika adanya peristiwa musibah kematian yang terjadi di tengah mereka ketika perantau tersebut meninggal dalam kondisi sendiri dan sakit, tanpa keluarga atau sanak keluarga di Jakarta. Sehingga Hanafi (38 tahun, pengemudi bajai) sebagai sahabat dekatnya merasa prihatin karena mayat dibiarkan dalam kondisi membusuk dan diberi parfum, kopi, serta kapur barus di kontrakannya. Hal ini menggerakkan niatnya untuk mengajak teman-temannya bergabung dalam komunitas "Paguyuban Perantau Berkah Nusantara" yang dilakukannya dengan mengajak, menyeru kepada kebaikan, persaudaraan dan rasa kepedulian di antara mereka. Satu demi satu akhirnya teman-temannya bergabung (Hanafi, Wawancara tanggal 12 Oktober 2017). Hal ini sesuai dengan teori tujuan berkomunikasi (Atabik (2014: 1), dimana komunikasi bertujuan untuk menumbuhkan respon dakwah (partisipasi) atas ide-ide atau pesan-pesan yang disampaikan oleh da'i (LTM NU) sehingga terjadi perubahan sikap dan tingkah laku yang diharapkan, sesuai dengan ajaran Al-Qur'an dan hadits sebagai sumber ajaran Islam.

Dari hasil wawancara diketahui bahwa di antara anggota komunitas ini ternyata ada ustaz, ada yang qoriah wanita lulusan madrasah dan ada yang bisa mengajar mengaji, dan ada menjadi Imam masjid. Ustaz Mazmun adalah salah satu pengemudi bajaj yang menjadi ustaz, setelah bekerja pada sore harinya ia membuka pelajaran mengaji bagi anak-anak pemulung di Jakarta Pusat. Bahkan sebagian ada anak-anak dari keturunan Tionghoa ikut serta belajar dan masuk Islam disana. Setiap hari beliau mengajar sekitar 185 anak-anak pemulung, anak jalanan di musholla kecil, hingga saat ini tenaga pengajarnya hanya 12 orang. Dan menurut Hanafi LTM NU sudah memberikan bantuan untuk sumbangan honor tenaga pengajar disana. Hal ini merupakan rencana ke depan LTM NU dalam pengadaan sarana dan fasilitas pengadaan Al-Qur'an dan lain-lain untuk mewujudkan kepedulian sosialnya disana (Hanafi, Wawancara tanggal 12 Oktober 2017).

Sehubungan dengan gerakan LTM NU dalam mewujudkan kepedulian sosial LTM NU bertanggung jawab dan andil dalam menyikapi kebutuhan masyarakat urban yang menjadi pengikut dari program kegiatan mudik bareng 
yang diadakan LTM NU setiap tahun. Dalam mewujudkan kepedulian sosial LTM NU memulainya dengan memberikan sentuhan psikologis kepada komunitas pengemudi di Jakarta Pusat ketika salah satu dari mereka tertimpa musibah (meninggal dunia) tanpa ada yang tahu jenazah harus diperlakukan seperti apa. Realisasi niat baik ini pun terelisasi dari LTM NU, yang melihat kebutuhan umatnya.

Setelah komunitas pengemudi tersebut mengikuti mudik gratis, akhirnya terbentuklah komunikasi persuasif dari Ustaz Mujahiddin sebagai da'i (komunikator) yang turut mengaplikasikan komunikasi dakwah persuasif kepada sasaran dakwah dalam hal ini komunitas masyarakat dhuafa yang mengikuti taklim di pengajian LTM NU setiap minggu ketiga di masjid An-Nadlah PBNU. Beliau mendengarkan, dan menjawab kebutuhan spiritual dari sikap komunitas pengemudi dengan membuat ruang untuk mereka di LTM NU. Komunikasi tersebut menghasilkan kesimpulan bahwa LTM NU memberikan ruang bagi para komunitas pengemudi dan keluarganya untuk belajar agama Islam. Menurut Hanafi saat ini warga pengemudi merasa belum punya payung untuk berteduh, mereka melihat agama Islam sudah tidak murni lagi. Dan hati mereka menginginkan kebenaran ajaran Islam dari ulama-ulama.

Data tentang daerah yang menjadi pos-pos pengemudi di Jakarta Pusat dalam setiap kegiatan baik dalam komunikasi maupun interaksi antar para pengemudi berada di titik pos-pos yang dijadikan area pendataan lokasi di mana mereka berkumpul.

Tabel 2. Komunitas Pengemudi (Paguyuban Perantau Nusantara) di Jakarta

\begin{tabular}{lll}
\hline Post Area & Lokasi & Wilayah \\
\hline Pos 1 & Pulo gundul, Tanah Tinggi & Jakarta Pusat \\
Pos 2 & Sedap malam, Samping Universitas P3I, Atrium & Jakarta Pusat \\
Pos 3 & Kembang Sepatu, Pasar Senen & Jakarta Pusat \\
Pos 4 & Duren Sawit & Jakarta Timur \\
Pos 1 & Kampung Jawa, gang Kancil & Jakarta Barat \\
Pos 2 & Roxy Grogol, gang Setiakawan & Jakarta Barat \\
Pos 3 & Jelambar Selatan, gang Irian & Jakarta Barat \\
\hline
\end{tabular}

Sumber: Wawancara Penelitian

Keinginan warga komunitas selanjutnya direalisasikan dalam bentuk taklim, pengajian yang diadakan sebulan sekali oleh LTM NU pada setiap minggu ketiga. Komunitas pengemudi tersebut selanjutnya dibina, diberi pengetahuan tentang akidah rukun Islam dan rukun Iman setiap minggu ketiga. Dalam menyampaikan pesan dakwah da'i (Ustaz Ali Sobirin, Ustaz Mansur) dalam materi dakwahnya menggunakan bahasa dakwah, dalam Al-Qur'an kata-kata qawlan maisura digunakan untuk menyampaikan pesan dakwah yang ringan sederhana dan pantas atau yang mudah diterima oleh madu secara spontan tanpa harus melalui pemikiran yang berat (Mubarok, 2009: 181). Solusi dengan dakwah bil hal pada taklim tersebut yaitu dengan membantu mereka saat mereka tertimpa musibah 
misalnya kematian. LTM NU sudah memberikan pelayanan dalam mengurus jenazah Zaini Yusuf (warga yang baru mengikuti pengajian satu kali) dengan fasilitas ambulan sampai ke tempat tinggalnya dan uang santunan duka cita. Pengajian taklim tersebut diikuti sekita kurang lebih 150 orang komunitas pengemudi yang akhirnya bukan hanya pengemudi, tetapi juga mengajak juga para ibu-ibu sebagai pedangang minuman, penjual nasi warteg ikut bergabung sehingga terbentuk civilization dalam dakwah. Wilayah mereka akhirnya melebar hingga ke Jakarta Barat dan membuat pos-pos kesatuan (lihat tabel 2). Hal ini sesuai dengan pendapat Ahmad Sutarmadi (2012: 113) yang mengatakan bahwa pengurus masjid diharuskan dapat berkomunikasi dengan anggota jamaah, masyarakat disekitar masjid dan dengan pemerintah serta pimpinan umat. Komunikasi tersebut bertujuan untuk mengarahkan agar lebih baik lagi keadaannya, mengubah situasi ke arah lebih baik yaitu sikap, perilaku yang bermafaat dari stake holder LTM NU kepada komunitas pengemudi di Jakarta Pusat. Sehingga komunikasi ysng baik membuat lembaga masjid lebih eksis dan berguna bagi kesejahtaeraan lahir batin umat pada umumnya.

Salah satu kegiatan dakwah LTM NU dalam memakmurkan masjid terhadap komunitas pengemudi di Jakarta Pusat berada di masjid An-Nadlah PBNU. Komunitas keluarga pengemudi di Jakarta Pusat membuat pengajian taklim. Kegiatan- kegiatan dakwah ini merupakan pengembangan respon dakwah dari kepedulian LTM NU bagi pengembangan dan peningkatan spiritualitas bagi keluarga komunitas pengemudi untuk mencari kebenaran Islam dan menjaga ukhuwah Islamiyah. Berikut jadwal kegiatan pengajian taklim pengemudi di Masjid Nadlah PBNU selama Mei-September 2017.

Tabel 3. Jadwal Pengajian Taklim Pengemudi Jakarta Pusat di Masjid An-

Nadlah

\begin{tabular}{|c|c|c|c|c|c|}
\hline $\begin{array}{l}\text { Waktu/ } \\
\text { hari }\end{array}$ & Materi Kajian & $\begin{array}{l}\text { Pembawa } \\
\text { Materi }\end{array}$ & $\begin{array}{l}\text { Jumlah } \\
\text { Peserta }\end{array}$ & $\begin{array}{l}\text { Bentuk } \\
\text { kegiatan }\end{array}$ & Keterangan \\
\hline $\begin{array}{l}\text { Minggu ke } 3 \\
\text { Mei } 2017\end{array}$ & Salat & Ali Sobirin & 150 orang & $\begin{array}{l}\text { Ceramah } \\
\text { dan diskusi }\end{array}$ & \\
\hline $\begin{array}{l}\text { Minggu ke } 3 \\
\text { Juni } 2017\end{array}$ & Salat Khusyu & Ali Sobirin & 125 orang & $\begin{array}{l}\text { Ceramah } \\
\text { dan diskusi }\end{array}$ & $\begin{array}{l}\text { Pembagian batik } \\
\text { NU kepada } \\
\text { anggota. }\end{array}$ \\
\hline $\begin{array}{l}\text { Minggu ke } 3 \\
\text { Juli } 2017\end{array}$ & Cara Sehat Mandiri & Ali sobirin & 145 orang & $\begin{array}{l}\text { Ceramah } \\
\text { dan diskusi }\end{array}$ & \\
\hline $\begin{array}{l}\text { Minggu ke } 3 \\
\text { Agustus } \\
2017\end{array}$ & $\begin{array}{l}\text { Pentingnya } \\
\text { silaturahmi }\end{array}$ & Ali Sobirin & 300 orang & $\begin{array}{l}\text { Halal bil } \\
\text { balal }\end{array}$ & \\
\hline $\begin{array}{l}\text { Minggu ke } 3 \\
\text { September } \\
2017\end{array}$ & $\begin{array}{l}7 \\
\text { langkah Percepatan } \\
\text { rezeki }\end{array}$ & $\begin{array}{l}\text { KH Mansur } \\
\text { Syaerozi }\end{array}$ & 180 orang & $\begin{array}{l}\text { Ceramah } \\
\text { dan diskusi }\end{array}$ & \\
\hline
\end{tabular}

Sumber : Wawancara dalam Penelitian

Berdasarkan tabel 2 diketahui bahwa kegiatan pengajian bagi keluarga 
komunitas pengemudi dilakukan secara rutin di minggu ke-3 setiap bulannya. Kegiatan ini dilakukan dalam bentuk ceramah dan diskusi keagamaan yang dipimpin oleh ustad yang cukup dikenal di masyarakat.

Saat ini beberapa program revitalisasi tersebut sudah dilaksanakan dan masih sedang dilaksanakan, sedang sebagian lagi belum diselesaikan secara optimal, karena kecenderungan permasalahan yang ditemukan pada pembiayaan operasional kegiatan tersebut. Pengumpulan dana tambahan dari donator, gizmas, saat ini sedang berjalan. Selain itu masih kurangnya tenaga professional untuk training dan kegiatan tersebut. Walaupun perekrutan muharrik di seluruh cabang di nusantara sudah dilaksanakan. Menurut ustaz Arif, (sekertaris LTM NU) sistem teknologi informasi juga akan diaplikasikan dna direalisasikan untuk membina para muharrik LTM NU diseluruh nusantara agar semua terdata dan terkoordinir dengan baik (wawancara, 10 Oktober 2017).

Dampak mengikuti pengajian taklim LTM NU bagi komunitas pengemudi di Jakarta Pusat memberikan manfaat keberkahan juga menimbulkan kesadaran beragama pada komunitas pengemudi. Hal ini sesuai dengan pendapat Ahmad Sutarmadi (2012: 55) dalam mengoptimalkan fungsi masjid sebagai pendidikan, dimana komunitas akhirnya tidak meninggalkan masjid namun mengajak kawan dekatnya untuk ikut serta selalu hadir di masjid, beribadah dan mendapatka siraman rohani yang mereka butuhkan dalam rangka memberikan pencerahan terhadap permasalahan umat. komunitas pengemudi di Jakarta Pusat. LTM NU sebagai pemimpin atau pelayan umat memberikan sesuatu baik dari segi moral, material kepada komunitas pengemudi dalam pengajian taklim yang diadakan LTM NU setiap minggu ketiga. Tumbuhnya kesadaran beragama pada komunitas pengemudi tersebut merupakan kesadaran seseorang bahwa Allah senantiasa menyertai hidup dan menyertai aktivitasnya. Karena beragama merupakan fitrah seseorang yang mengalami perkembangan secara alamiah dan ada yang sesuai kehendak Allah. Dalam kriteria kematangan dan kehidupan beragama Syamsu Yusuf (dalam Mu'awanah, 2009: 16) menyebutkan antara lain memilki kesadaran bahwa setiap perilakunya tidak terlepas dari pengawsan Allah, adanya pengamalaan ibadah ritual secara ikhlas dan mampu mengambil hikmah dari ibadah tersebut dalam kaitannya dengan kehi dupan sehatri-hari, memiliki penerimaan secara positif akan irama/romantika kehidupan yang ditetapkan Allah dan selalu bersyukur saat mendapat anugerah, memperkokoh ukbuwah islamiyah dan insaniah, serta senantiasa menegakkan amr makruf nabi munkar. Kesadaran beragama ini akan menumbuhkan kualitas-kualitas moral dan keluhuran budi pekerti manusia sehingga kesdaran ketuhanan yang membebaskan dirinya dari derita kehampaan spiritual yang banyak menimpa manusia/umat saat ini (Ismail, 2015: 49).

Dalam komunitas kelompok tersebut kemudian terjadi interaksi sosial serta komunikasi diantara komunitas. Dalam ilmu komunikasi lingkungan dan objek berpengaruh dalam komunikasi,sehingga adanya unsur kesamaan budaya maka 
komunikasi yang terjalin semakin efektif (Ilaihi : 2013 : 12). Tanpa disadari kelompok komunitas ini memiliki nilai-nilai kultural, keyakinan yang sama, budaya yang sama. Dalam budaya organisasi dikatakan bahwa dengan adanya kesamaan aturan, norma, keyakinan dan falsafah yang menjadi way of life maka kelompok akan memiliki kerekatan dan kedekatan satu sama lain (Prawironegori, 2016). Pembentukan jamaah di masjid tersebut sebagai ikatan salat di dalamnya sehingga diluarnya menjadi kesatuan sosial muslim. kesatuan sosial tersebut merupakan kesatuan suku/daerah tertentu yang memancar dari ibadah di masjid, sehingga menjadi unsur-unsur kebudayaan Islam (Gazalba, 2001: 150).

Menurut Mujahidin, revitalisasi ke depan LTM NU terhadap komunitas pengemudi di Jakarta Pusat yaitu dengan mengadakan program jaminan hari tua bagi pengemudi mikrolet, bajai, ojek dengan membuat tabungan bersama dan dikelola bersama. Semacam koperasi simpan pinjam untuk solusi ekonomi darurat. Diadakan acara silaturahmi halal bil halal minimal 1 tahun 1 kali di daerah mereka, membuktikan bahwa di Jakarta mereka punya bukti bahwa mereka menjadi bagian komunitas NU sehingga ilmu yang mereka dapatkan bisa di manfaatkan di kampung halaman misalnya dengan mengajarkan memandikan jenazah, membantu anak anak yang tidak mampu di kampung halaman, atau menjadi pengurus masjid di daerahnya.

Selain membuat program ke depan dengan membuat tabungan dari mereka untuk mereka (koperasi syariah) sekaligus memupuk rasa kepedulian anggota komunitas dengan memberikan sumbangsihnya dalam bentuk uang kas per minggu dan mengajarkan mereka bersedekah, memberi infaq dsb. LTM NU juga memberikan sentuhan psikologis ke hati mereka dengan adanya taklim di masjid PBNU dan para jamaah diberikan makanan juga minuman secara gratis bahkan baju batik. Selain itu LTM NU dalam komunikasi persuasive dengan jamaah selalu menampung aspirasi drivers. Keinginan mencari kebenaran agama dari para ulama menumbuhkan semangat dalam beribadah dan memiliki ilmu tentang ajaran Islam terutama rukun Islam, rukun Iman yang bisa menjadi pondasi keimanan mereka. Karena ketika mereka memiliki akhlak karena mereka sesungguhnya pelayan bagi masyarakat pengguna kendaraan di kota Jakarta. Tujuannya agar mereka menjadi pengemudi yang sopan, ramah, dan tidak membohongi orang yang naik kendaraan tersebut, apalagi orang tersebut masih baru di Jakarta dan tidak tahu jalan. Membentuk kesatuan umat sebagai perantau Berkah Nusantara agar mereka saling peduli satu sama lain ketika terjadi musibah misalnya meninggal dunia. Meningkatkan kesadaran beragama anggota pengemudi agar lebih takwa dan lebih beriman. Berikut kegiatan aksi program LTM NU yang sudah dilaksanakan dan tindak lanjut kegiatannya. 
Tabel 4. Revitalisasi LTM NU yang sudah dilaksanakan dan rencana kegiatan selanjutnya.

\begin{tabular}{|c|c|c|c|}
\hline $\begin{array}{l}\text { Jenis } \\
\text { Kegiatan }\end{array}$ & $\begin{array}{l}\text { Waktu } \\
\text { pelaksanaan }\end{array}$ & $\begin{array}{l}\text { Jumlah anggota } \\
\text { /sasaran }\end{array}$ & Keterangan \\
\hline $\begin{array}{l}\text { BBM } \\
\text { BERKAH } \\
\text { (bersih-bersih } \\
\text { masjid) }\end{array}$ & tentatif & $\begin{array}{l}\text { Berlaku kegiatan di } \\
\text { seluruh masjid di } \\
\text { Indonesia }\end{array}$ & $\begin{array}{l}\text { Sudah berjalan dan sudah punya } \\
\text { mobil BBM. }\end{array}$ \\
\hline $\begin{array}{l}\text { Mudik bareng } \\
\text { gratis }\end{array}$ & $\begin{array}{l}\text { Sudah } 2 \mathrm{x} \\
\text { pelaksanaan } \\
\text { tahun } 2016 \text {, } \\
\text { Juli } 2017\end{array}$ & $\begin{array}{l}2 \text { bus, diikuti warga } \\
\text { kurang mampu } \\
\text { seperti pedangan } \\
\text { asongan, pemulung, } \\
\text { pengemudi mikrolet, } \\
\text { ojek, bajai dll. }\end{array}$ & \\
\hline $\begin{array}{l}\text { GISMAZ } \\
\text { (gerakan infak } \\
\text { sadaqah } \\
\text { masjid dan } \\
\text { masyarakat) }\end{array}$ & tentatif & $\begin{array}{l}\text { Muharrik NU di } \\
\text { Seluruh PWC MWC } \\
\text { dan PR }\end{array}$ & $\begin{array}{l}\text { Sudah berjalan diseluruh } \\
\text { Indonesia }\end{array}$ \\
\hline $\begin{array}{l}\text { Pelayanan } \\
\text { Taklim } \\
\text { Paguyuban } \\
\text { Perantau } \\
\text { Nusantara }\end{array}$ & $\begin{array}{l}\text { Setiap bulan } 1 \\
\text { x pertemuan di } \\
\text { Minggu ke - } \\
3 / 4\end{array}$ & $\begin{array}{l}\text { 150-180 orang terdiri } \\
\text { dari: pengemudi bajai, } \\
\text { mikrolet, ojek, taksi, } \\
\text { pedangan asongan, } \\
\text { pemulung, pedangang } \\
\text { warteg serta } \\
\text { keluarganya. }\end{array}$ & $\begin{array}{l}\text { Sudah } 6 \text { x pelaksanaan di masjid } \\
\text { An-Nadlah PBNU sejak Juni } \\
2017 \text { sampai sekarang. }\end{array}$ \\
\hline $\begin{array}{l}\text { Pelatihan Salat } \\
\text { sempurna cara } \\
\text { rasullulah }\end{array}$ & $\begin{array}{l}\text { Dilaksanakan } \\
\text { tanggal 20,21 } \\
\text { sept } 2017 \mathrm{di} \\
\text { Vila Cimacan } \\
\text { Puncak }\end{array}$ & $\begin{array}{l}\text { Diikuti anggota } \\
\text { PBNU Di Jakarta dan } \\
\text { sekitarnya }\end{array}$ & $\begin{array}{l}\text { Tujuannya: mempersiapkan } \\
\text { muharrik masjid untuk } \\
\text { penggerka dakwah seluruh } \\
\text { cabang PBNU. Hasilnya: } \\
\text { ditemukan ustaz mazmun yang } \\
\text { mampu mengajar setiap hari } \\
\text { sehabis magrib jamaah berjumlah } \\
185 \text { orang anak pemulung utnuk } \\
\text { belajar mengaji. Hanafi, yang } \\
\text { memiliki pesantren di tegal. Ibu } \\
\text { Addah yang qoriah terbaik dan } \\
\text { lulusan madrasah. }\end{array}$ \\
\hline $\begin{array}{l}\text { Kursus bahasa } \\
\text { arab }\end{array}$ & Selasa & & \\
\hline $\begin{array}{l}\text { Pelayanan } \\
\text { Bagi jamaah } \\
\text { yang kena } \\
\text { Musibah Bagi } \\
\text { Paguyuban } \\
\text { Perantau } \\
\text { Nusantara }\end{array}$ & $1 \times$ pelayanan & $\begin{array}{l}\text { Almarhum bpk } \\
\text { Zaini Yusuf ( } 60 \\
\text { tahun). Sudah } \\
\text { mengikuti taklim satu } \\
\text { kali, lalu } \\
\text { meninggal karena } \\
\text { sakit darah tinggi di } \\
\text { kontrakannya. }\end{array}$ & $\begin{array}{l}\text { Jenazah diantarkan ke lokasi } \\
\text { pemakaman dengan mobil } \\
\text { ambulan LAZIZNU dan diberi } \\
\text { dana santunan dari LTM PBNU. }\end{array}$ \\
\hline
\end{tabular}




\begin{tabular}{|c|c|c|c|}
\hline $\begin{array}{l}\text { Bantuan } \\
\text { sarana alquran } \\
\text { dll untuk } \\
\text { pengajian } \\
\text { taklim umat }\end{array}$ & $\begin{array}{l}1 \mathrm{x} \text { bantuan } \\
\text { honor bagi } \\
\text { tenaga } \\
\text { pengajar }\end{array}$ & $\begin{array}{l}\text { Pengajian anak } \\
\text { pemulung di Jakarta } \\
\text { pusat oleh ustaz } \\
\text { Mazmun, anggota } \\
185 \text { orang. }\end{array}$ & $\begin{array}{l}\text { Panning kedepan: sarana al quran } \\
\text { dll. }\end{array}$ \\
\hline $\begin{array}{l}\text { Pelatihan } \\
\text { Khotib, } \\
\text { marbot, } \\
\text { Muadzin, } \\
\text { remaja masjid }\end{array}$ & Planning & & \\
\hline $\begin{array}{l}\text { Membentuk } \\
\text { ekonomi } \\
\text { berbasis } \\
\text { masjid } \\
\text { (koperasi, } \\
\text { tabungan } \\
\text { simpan } \\
\text { pinjam dll.) }\end{array}$ & Planning & & \\
\hline $\begin{array}{l}\text { Membuat } \\
\text { lembaga } \\
\text { kesehatan } \\
\text { berbasis } \\
\text { masjid }\end{array}$ & Planning & & \\
\hline $\begin{array}{l}\text { Membuat } \\
\text { jaminan hari } \\
\text { Tua bagi } \\
\text { warga } \\
\text { Paguyuban } \\
\text { Perantau } \\
\text { Nusantara }\end{array}$ & Planning & & \\
\hline $\begin{array}{l}\text { Diadakan } \\
\text { ruang } \\
\text { silaturahim } 1 \\
\text { tahun } 1 \times \text { di } \\
\text { daerah } \\
\text { paguyuban } \\
\text { perantau } \\
\text { nusantara }\end{array}$ & Planning & & $\begin{array}{l}\text { Tujuannya untuk membuktikan } \\
\text { bantuan-bantuan LTM NU bisa } \\
\text { bermanfaat untuk umat } \\
\text { disana/musala/masjid } \\
\text { disana.(daerah paguyuban). }\end{array}$ \\
\hline
\end{tabular}

Sumber : Wawancara dalam Penelitian

Data dalam tabel 4 menggambarkan kegiatan revitalisasi LTM NU yang memiliki kepedulian sosial terhadap komunitas pengemudi di Jakarta Pusat. Dari aksi program revitalisasi LTM NU yang menjadi rencana tindak lanjut revitalisasi masjid adalah GIZMAS (gerakan infak, zakat, sadaqoh memakmurkan masjid) dan BBM (Bersih-Bersih Masjid). Sampai saat ini program GIZMAS dan BBM sudah berjalan bahkan BBM memberikan lapangan kerja pada muharik untuk membuka laundry. Kegiatannya tidak hanya bersih-bersih fisik masjid, tetapi juga bersih-bersih nalar dan hati. Bersih-bersih nalar seperti meningkatkan 
pengetahuan takmir dan jamaah masjid berupa pembinaan atau penyuluhan dalam rangka menghidupkan masjid sebagai pusat pelayanan jamaah, mengadakan pelatihan GISMAS (Gerakan Infak Sedekah Memakmurkan Masjid dan Masyarakat) atau menggelar pelatihan manajemen masjid ramah pemuda (Hidayatullah, 2018). LTM PBNU dalam hal ini juga memberikan hibah perangkat alat-alat pembersih masjid kepada tim BBM Berkah dari beberapa kabupaten dan kota, program BBM Berkah tersebut akan dilaksanakan serentak di seluruh Indonesia. (NU Online: 2018).

\section{PENUTUP}

Dari penelitian di atas dapat disimpulkan bahwa revitalisasi masjid melalui program LTM NU efektif dan sudah terlihat hasilnya. Namun, kegiatan yang dilakukan LTM NU masih perlu penguatan dan monitoring yang continue. Peningkatan program dan kegiatan LTM NU juga harus lebih dikembangkan guna meningkatkan keimanan dan kebersamaan persatuan umat Islam.

Dampak revitalisasi LTM NU bagi masyarakat, khususnya bagi komunitas pengemudi di Jakarta Pusat adalah menumbuhkan kesadaran agama mereka. Kepedulian sosial LTM NU mampu menjawab kebutuhan dan menjadi problem solving komunitas pengemudi di Jakarta Pusat. Hal ini bisa terwujud karena LTM NU melakukan komunikasi dakwah persuasif yang efektif dalam menjawab kebutuhan umat. Hasil kegiatan kepedulian sosial LTM NU membentuk komunitas baru (civilization) dakwah.

Revitalisasi LTM NU memberikan perubahan dalam mengoptimalkan fungsi masjid dimana upaya memakmurkan masjid bukan hanya sebagai tempat ibadah salat namun juga peningkatan kegiatan dakwah. Keterlibatan komunitas pengemudi di Jakarta pusat dalam merespon positif komunikasi persuasif LTM NU menjadi wujud kepedulian sosial LTM NU dalam merealisasikan program aksi revitalisasi LTM NU. Dari kegiatan tersebut menujukkan bahwa adanya jalinan ukhuwah Islamiyah antara LTM NU dan komunitas pengemudi di Jakarta Pusat.

Dalam revitalisasi LTM NU ditemukan pioneer dakwah baru sebagai mubarrik dakwah di dalam komunitas pengemudi di Jakarta. Sehingga mampu menjadi pemimpin sekaligus pelayan di komunitas pengemudi Jakarta Pusat. Revitalisasi LTM NU memiliki pengaruh positif pada sasaran dakwah dalam basis pengoptimalan masjid sebagai pusat pendidikan, ilmu pengetahuan, memajukan perekonomian umat dan menyatukan ukhuwah Islamiyah masyarakat.

Aktivitas dakwah dalam LTM NU mengalami proses perubahan dan memainkan peran-peran antisipatif yang sangat strategis. Dakwah menjadi sebuah gerakan yang merupakan salah satu institusi sosial hidup di tengah dinamika masayrakat melakukan proses sosial dalam berinteraksi di masyarakat perkotaan. Karena dakwah sejatinya mampu berfungsi sebagai pengendali perubahan terutama dalam proses tranformasi nilai-nilai sosial dan budaya untuk membentuk 
tatanan baru atau membaharukan kembali suatu tatanan yang dianggap telah kehilangan nilai relevansinya dalam mewujudkan kepedulian sosial khususnya pada komunitas pengemudi Jakarta di tengah arus modernisasi dan pola kota metropolitan Jakarta.

LTM NU sebagai basis gerakan dakwah Aswaja diharapkan lebih meningkatkan pelayanan kepada masyarakat dan kepemimpinannya sebagai lembaga yang kompeten serta solusif di masa mendatang, sesuai dengan kebutuhan masyarakat sebagai titik utama sasaran kegiatan LTM NU di mana kelompok kecil masyarakat urban membutuhkan pengayoman serta wadah/ruang spiritualitas dalam beragama.

Penelitian ini diharapkan bisa menjadi bahan rujukan dalam pengembangan manajemen masjid dan menjadi evaluasi program kegiatan revitalisasi LTM NU ke depan yang lebih baik. Kepedulian sosial LTM NU dalam merevitalisasi fungsi masjid hendaknya tetap konsisten dan terus-menerus sehingga mampu menjaga ukbuwah Islamiyah dan tetap menjadi problem solving umat dalam dakwah Aswaja yang rabmatan lil 'alamin.

\section{DAFTAR PUSTAKA}

Almanhaj. (2017). Pengertian Masjid. diakses 11 Oktober 2017 dari https://almanhaj.or.id/2524-pengertian-masjid.html,

Atabik, A. (2014). Konsep Komunikasi Dakwah Persuasif dalam Perspektif AlQur'an. AT-TABSYIR, Jurnal Komunikasi Penyiaran Islam. 2(2), 117-36.

Depag RI. (2008). Al-Qur'an dan Terjemahannya. Bandung: Diponegoro.

Depdiknas. (2015). Kamus Besar Bahasa Indonesia, Jakarta: Pusat Bahasa. Edisi Ke4.

Duta (2018). Ajak Pemuda Kembali ke Masjid, Jaga NKI, LTM PBNU Gelar BBM Berkah Serentak se-Indonesia. diakses 26 Maret 2018 dari https://duta.co/ajak-pemuda-kembali-ke-masjid-jaga-nkri-ltm-pbnugelar-bbm-berkah-serentak-se-indonesia/.

Fakhruroji, M. (2017). Dakwah di Era Media Baru : Teori dan Aktivisme Dakwah di Internet. Bandung: Simbiosa Rekatama.

Gazalba,. (2001). Masjid Pusat Ibadah dan Kebudayaan Islam, Jakarta: Al Husna Zikra

Gerungan, W.A. (1996). Psikologi Sosial. Bandung: Eresco

Hanafi. (2017).Wawancara, Pengemudi Bajai. Pulo Gundul Pos 1 Tanah Tinggi, Kec.Johar Jakarta Pusat

Hasanah, S. U. (2011). Memoar Dakwah, Jakarta: Pusat Pengembangan Pendidikan Agama dan Sosial

Hidayatullah. (2018). LTM PBNU Luncurkan Gerakan BBM Berkah. dikses 26 Juni 2018 dari 
https://www.hidayatullah.com/berita/nasional/read/2018/05/11/14208

8/ltm-pbnu-luncurkan-gerakan-bbm-berkah.html

Husin, B. (2011). Fungsi masjid dalam Perspektif Al-Qur'an dan As-Sunnah, 2

(1) Spektra, Jurnal Ilmu Sosial.

Mandzur, I. (2002). Lisan al-Arab. Kairo: Darul hadis

Iimaziah. (2012). Kepedulian Sosial diakses tanggal 12 Oktober 2017 dari https://iimazizah.wordpress.com/2012/12/18/kepedulian-sosial/

Ilaihi, W. (2013). Komunikais Dakwah. Bandung: Remaja Rosdakarya

Ismail, I. (2013). True Islam. Jakarta: Mitra Wacana Media

LTM NU, (2015). Masjid Benteng Pertahanan NU \& NKRI, Jakarta: LTM PBNU

LTM NU. (2017). Pedoman mubarrik dan Ta'mir masjïd NU. Jakarta: LTM PBNU

Mcelmeel, S. L. (2002). Character education, A Book Guide For Theacher, Librarians, And Parents, Greenwood Village, Colorado: Teacher Ideas Press

Mu'awanah, E., \& Hidayah, R. (2009). Bimbingan Konseling Islami di Sekolah Dasar, Jakarta: Bumi Aksara

Mubarok, A., (2009). Psikologi Dakwah, Jakarta: Pustaka Firdaus

NU Online. (2018). Besok, LTM PBNU Luncurkan Bersib-Bersib Masjid Serentak diakses 26 Juni 2018 dari http://www.nu.or.id/post/read/90075/besokltm-pbnu-luncurkan-bersih-bersih-masjid-serentak

Sugiyarbini. (2012). Teori Psikologi Individu Adler. , diakses pada 12 oktober 2012 dari (http://sugithewae.wordpress.com/2012/05/05/teori-psikologiindividu-adler/

Suhandang, K. (2014). Strategi Dakwah; Penerapan Strategi Komunikasi dalam Dakwah, Bandung: Remaja Rosdakarya

Sutarmadi, A. (2012). Manajemen Masjid Kontemporer, Jakarta: Media Bangsa

Yaumi, M. 2014. Pendidikan Karakter Landasan, Pilar dan Implementasi. Jakarta: Prenanda media

Zuchdi, D. (2011). Pendidikan Karakter Dalam Prespektif Teori dan Praktek. Yogyakarta: UNY Press

\section{Wawancara}

Arif. (2017). W awancara dengan sekertaris LTM PBNU,Jakarta; Lantai 4 PBNU, Kramat Raya

Addah. (2017). Wawancara. Anggota Pengajian Komunitas Pengemudi LTM NU. Jakarta: Tanah Tinggi, Pulo gandul, kec. Johar

Muhajiddin. 2017. Wawancara LTM NU, Jakarta: PBNU

Sobirin, A. (2017). Wawancara. Pemateri Kajian Dakwah Islam Taklim Komunitas LTM NU. Jakarta: Kantor LTM NU PBNU 